(1) 10

\title{
Longing is in the memory of the beholder: Collective nostalgia content determines the method members will support to make their group great

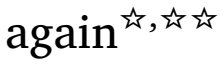

\author{
Michael J.A. Wohl ${ }^{\mathrm{a}, *}$, Anna Stefaniak ${ }^{\mathrm{a}}$, Anouk Smeekes ${ }^{\mathrm{b}}$ \\ a Carleton University, Ottawa, Canada \\ ${ }^{\mathrm{b}}$ Utrecht University, Utrecht, Netherlands
}

\section{A R T I C L E I N F O}

\section{Keywords:}

Collective nostalgia

Prejudice

Social representations

History

Immigration

\begin{abstract}
A B S T R A C T
Across four studies, we tested whether the content of collective nostalgia has untapped utility for understanding intergroup relations. In Study 1a, we demonstrated variance in the content of the nostalgizing American Christians report-variance that influenced attitudes towards outgroups. Participants who reported longing for a more open society expressed less anti-immigration sentiments and less blatant prejudice against Muslims compared to those longing for a more homogeneous society. In Study 1b, we replicated these results using a representative sample of Poles, thus extending them to a different socio-political context. In Study 2, we demonstrated that the content of collective nostalgia experienced can be experimentally manipulated. Specifically, experimentally primed openness-focused nostalgia (relative to a control condition) weakened American Christians' anti-immigration sentiments (but not blatant prejudice against Muslims). Study 3 replicated the results of Study 2 with an improved experimental manipulation. Overall, the findings show significant effects that content of collective nostalgia has on anti-immigration sentiments as well as some indication that the content of collective nostalgia influences blatant intergroup prejudice. These results have theoretical relevance for the study of collective nostalgia (i.e., content matters) as well as practical relevance in demonstrating that variations in nostalgia-inducing rhetoric can shape intergroup attitudes.
\end{abstract}

People often find comfort in the belief that their social group-at its core-remains stable despite the changing times and generations (Sani, 2010). Not only does this belief help cultivate group solidarity, it also enhances the well-being of group members (Sani et al., 2008; Smeekes \& Verkuyten, 2013). Unsurprisingly then, group members try to foster a sense of an unchanging group (Sani et al., 2008). For example, the phrase l'dor v'dor ("from generation to generation") is a central theme in Judaism's liturgy and education, which conveys that Jews' past, present, and future are inter-connected (see Kahn et al., 2017). Contrariwise, people tend to experience psychological distress in the presence of a threat to their social group's stability (Jetten \& Wohl, 2012).

When threats to the group's stability are experienced, members often wax nostalgic (Byrne, 2007; Smeekes, 2015; Wildschut et al., 2014). Put another way, when people believe current social, cultural, and political realities have placed the stability of their social group in flux, they often experience collective nostalgia-sentimental longing or wistful reflection-for their group's past. The net effect are attitudes and action tendencies (e.g., support for policies) that aim to stabilize their group (Cheung et al., 2017)—a process that the nascent collective nostalgia literature suggests can result in action taken against those deemed to be outsiders or outgroups deemed to be threating the group's stability (e.g., anti-immigration; Smeekes et al., 2018).

In the current research, we examined the heretofore untested supposition that the consequence of collective nostalgia for intergroup relations is determined by the content of the collective memory experienced. To date, research examining collective nostalgia has treated the content of the experienced nostalgia as noise. We contend that doing so hinders the utility of collective nostalgia as a predictor of the

\footnotetext{
The authors declare that there are no potential conflicts of interest with respect to the research, authorship, and/or publication of this article. This research was

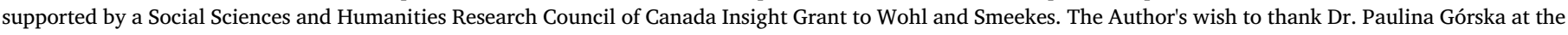

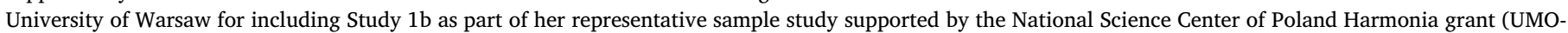
2017/26/M/HS6/00689).

4 4 This paper has been recommended for acceptance by Lasana Harris.

* Corresponding author at: Department of Psychology, Carleton University, 1125 Colonel By Drive, Ottawa, Ontario K1S 5B6, Canada.

E-mail address: michael.wohl@carleton.ca (M.J.A. Wohl).
} 
numerous means members try to reclaim the ingroup's treasured past. Undeniably, there is within group variation in how members represent ingroup history (see Liu \& Hilton, 2005), and thus the past that some group members may long to reclaim. Variation in the content of collective nostalgia should provide a signal that illuminates what actions members will support to help the group reclaim its collective continuity. In short, the content of collective nostalgia matters. It matters not only for expanding theory, but also the practical relevance of collective nostalgia.

Herein, we test for the possible presence of two separable forms of collective nostalgia: openness-focused nostalgia and homogeneity-focused nostalgia. Openness-focused nostalgia should be an outcome of a belief (measured or manipulated) that the ingroup is losing touch with its pluralistic roots and subsequent longing for a past in which the ingroup was more open or tolerant. The outcome of such nostalgizing should be more positive attitudes towards diversity and heightened support for policies and actions that help reclaim the ingroup's pluralism. Conversely, homogeneity-focused nostalgia should stem from a belief (measured or manipulated) that the ingroup is losing connection to its cultural and ethnic roots and subsequent longing for a past when there was greater adherence to ingroup norms and values. Such nostalgizing should manifest in rejection of outgroups (e.g., hostile intergroup attitudes). We tested the associations between collective nostalgia contents and intergroup attitudes across four studies in two distinct socio-political contexts (United States and Poland).

\section{The malleability of collective memory}

The stories that group members tell frame the ingroup's raison d'etre (i.e., reason for being) as enduring the vicissitudes of time (see Jetten \& Wohl, 2012). However, there is variance in the particular stories that members tell and remember (Liu \& Hilton, 2005; Sahdra \& Ross, 2007). That is to say, the stories members recount about the ingroup's past are not monolithic. This is because group history is not remembered as it was, but as group members need it to be. Variation exists because history is a social construction, designed to facilitate effective communication and coordination of behavior (Liu et al., 2002; Moscovici, 1988). The group constructs an understanding of its past to inform members who they are (i.e., group values, beliefs, and norms), where they came from (i.e., a shared history), and where they are going (i.e., a common fate; Liu \& Hilton, 2005; Moscovici, 1988; Wohl et al., 2012), which are then used as a resource to help navigate contemporary lived experiences.

Although collective memories are social constructions, they are not created in a vacuum. They are constructed to be consistent with the member's schema of the group (Sahdra \& Ross, 2007). Specifically, group members recall information that is consistent with their schema of the ingroup more than schema inconsistent information (see Roediger III et al., 2001). Sahdra and Ross (2007), for example, showed that Canadians who were motivated to remember their history favorably recalled fewer negative incidents during the history of Canada than participants who were less so motivated. This effect occurred despite strong demands for memory accuracy, which suggest the presence of a memory bias rather than self-presentational concerns. Moreover, they showed that this memory bias is highly susceptible to alteration (i.e., they were able to manipulate participants' motivation to recall Canadian history in a more favorable light). The fact that memories of the ingroup's history are malleable is in accord with research on a memory process called reconsolidation in which nuances about past events can be lost and misinformation added (see Shaw, 2016)—a situation that has implications for the politics of intergroup relations.

According to Blight (2001), group leaders often try to capitalize on the malleability of collective memory to achieve their political goals. They selectively distort the ingroup's past to achieve and maintain a positive image of the ingroup (Dresler-Hawke, 2005), and garner support for political action in the name of protecting the ingroup against perceived present and future threats (Bar-Tal, 2007; Wohl \& Branscombe, 2008). One way this can be achieved is via rhetoric that focuses attention on unwanted change the group is experiencing (Jetten \& Wohl, 2012). The benefit of doing so is that salient unwanted change elicits collective nostalgia-a group-based emotion that reflects sentimental longing for how the ingroup used to be. Specifically, collective nostalgia is experienced when group members have idealistic conceptions of events or features of the ingroup's past coupled with dissatisfaction with the ingroup's current lived experience (Cernat, 2010; Cheung et al., 2017; Wildschut et al., 2014). To put a dark line under the matter, collective nostalgia tends to place the past in a romantic light. In so doing, group members who experience collective nostalgia often want to act in ways that they believe, or that group leaders manipulate them to believe, will recapture the "glory days" (Smeekes, 2015; Wildschut et al., 2014).

Indeed, reactionary anti-immigrant movements are partially explained by collective nostalgia for a "purer" society of the past (Mols \& Jetten, 2014; Verkuyten, 2013). That is, collective nostalgia can reflect a longing for a more homogeneous society, with associated prejudices against perceived outgroup members. However, collective nostalgia may also serve to benefit intergroup relations. For example, Turner et al. (2018) found that nostalgic memory that is focused on shared experience with an outgroup member yields reduced prejudice towards the outgroup. Additionally, research has shown that some Americans report high levels of nostalgia for the 1960s, a decade known for its openness and freedom (Wilson, 2005).

\section{Why we need to focus on collective nostalgia content}

Unfortunately, the nascent literature on collective nostalgia has yet to illuminate when and why group members may pursue disparate paths to reclaim "the way we were". We contend that the reason for this lack of precision in predictive utility is that collective nostalgia has been treated as unitary group-based emotion. Specifically, research has solely examined the extent to which group members report collective nostalgia in light of various pre-conditions. For example, Wildschut et al. (2014; Study 3) asked participants to recall either a nostalgic event that they had experienced together with other ingroup members (i.e., the collective nostalgia condition) or an ordinary event that they had experienced together with fellow ingroup members (i.e., the collective ordinary condition), and then assessed between group differences in state nostalgia (e.g., "Right now, I am having nostalgic feelings"). Other studies (e.g., Cheung et al., 2017; Smeekes et al., 2015) have used items that directly mention nostalgia for the ingroup's past, but still only assess the extent to which the group-based emotion is experienced as a whole (e.g., "When thinking about [the ingroup], to what extent do you feel nostalgic about the way [ingroup members] were in the past"). Even in Turner et al. (2018) where the researchers focused participants' attention on a specific aspect of the ingroup's past (i.e., a shared past with an outgroup), they were simply asked if they "feel nostalgic at the moment".

Missing from the existing theory and research on collective nostalgia is an appreciation for the practical importance that the content of collective nostalgic reverie has for understanding the different ways group members may act to reclaim the ingroup past they believe (or are manipulated to believe) existed. Herein, we direct needed attention to the signal provided by the content of collective nostalgia-a signal that may illuminate the action tendencies group members are willing to support to reclaim a past that is believed to be losing connection with the present. In line with social identity theory (Tajfel \& Turner, 1986), group members may (consciously or less so) distort their memory of the ingroup's past to align with contemporary wants and desires (see de Vries \& Hoffman, 2018). In this light, differences in perceived group needs should lead members to emphasize different contents of their social identity. These 'contents' should manifest in variance in the nostalgic reflection of group members. 


\section{Overview of the current research}

In four studies conducted in two different national contexts (the United States and Poland), we tested for the presence of two general kinds of collective nostalgic reverie: collective nostalgia for a homogeneous society and collective nostalgia for an open society. Although there are likely other types of collective nostalgia, these two were of primary interest given their relevance to political discourse. In particular both right- and left-wing politicians employ nostalgia to galvanize social support for exclusionary or inclusive attitudes towards immigrant outgroups by selectively presenting these two aspects of the group's past as worth longing for and thus reclaiming (see Gaston \& Hilhorst, 2018).

It was hypothesized that variance in the extent to which group members experience either type of collective nostalgic reverie will have implications for intergroup relations. Specifically, we predicted that Americans (Studies 1a, 2, and 3) and native Poles (Study 1b) who feel collective nostalgia (measured in Studies 1a and 1b; manipulated in Studies 2 and 3) for a more homogenous society should express greater anti-immigration sentiments (i.e., a desire to keep outgroup members away from the ingroup) compared to those who feel collective nostalgia for a more open society. In light of the recent surge in right-wing political populism and nationalism around the globe (Greven, 2016) as well as the increasing theoretical interest in more blatant forms of intergroup hostility (e.g., blatant dehumanization, see Kteily \& Bruneau, 2017; Bruneau et al., 2018), we also wanted to test whether the effects of different contents of collective nostalgia would extend to a more blatant measure of prejudice directed at a specific religious minority within the in-group-Muslim Americans (in Studies 1a, 2, and 3).

A power analysis was conducted prior to Studies 1a, 2, and 3 to determine the necessary sample to obtain a small to moderate effect size as significant with $80 \%$ power for $p<.05$; the sample size in Study $1 \mathrm{~b}$ was determined based on the representativeness requirement and thus power analysis was not conducted. For Study 1a, we used $\mathrm{G}^{*}$ Power to determine the necessary sample size to detect a small to moderate correlation $(r=0.20)$ when the alpha is set at 0.05 . It was determined a sample size of 215 was required. In Study 2, we conducted a power analysis using $G^{*}$ power to detect the smallest theoretically meaningful effect size $(\beta=0.15)$ at $80 \%$ power when the alpha is set at 0.05 . It was determined a sample size of at least 343 was required. In Study 3, power analysis using $\mathrm{G}^{*}$ power that assumed a small to medium effect size $\left(f^{2}=0.13\right), 0.80$ power, and alpha of 0.05 suggested a required sample size of 558 . All materials and data from the presented research are publicly available via the Open Science Framework: https://osf.io/38s65/?view_only =

cb33e1c1013e42bfa116665883a22c0a

In Studies 1a, 2, and 3 we collected responses on several other measures for exploratory purposes (i.e., as a basis for new lines of research), including items that assessed ingroup identification, collective angst, and attitudes towards freedom of speech. Study $1 \mathrm{~b}$ was added to a larger study that measured a host of additional variables focused on social network embeddedness as a determinant of people's collective action engagement.

\section{Study 1a}

The primary purpose of Study 1a was to explore whether group members vary in the content of the collective nostalgia they experience. With a community sample of American Christians, we hypothesized that participants will differ in the extent to which they report sentimental longing for a more homogeneous American society or an American society that was more open to cultural and religious diversity. The secondary purpose was to assess the relation between contents of collective nostalgia and intergroup attitudes. We predicted that nostalgizing about a more open American society should be negatively associated with anti-immigration sentiments and blatant prejudice towards Muslims. In contrast, nostalgizing about a more homogeneous
American society should be positively associated anti-immigration sentiments as well as blatant prejudice against Muslims.

\subsection{Methods}

\subsubsection{Participants}

Two-hundred eighty-eight Mechanical Turk (Mturk) workers accessed the survey described as assessing "opinions about America's past, thoughts about various groups within America as well as thoughts on numerous US foreign and domestic policies." The call for participants noted that participation was restricted to American citizens residing in the United States who identify as Christian. Three participants did not consent to the study. Seventy-five workers were deemed ineligible because they indicated they were not Christian in the eligibility questionnaire, and thus were not permitted to complete the full survey. An additional eight participants withdrew immediately upon accessing the survey while one person did not answer any questions (without clicking the "withdraw" button) - they were removed from the sample. Thus, the final sample consisted of 201 American Christians (100 males, 96 females, 5 unidentified) who ranged in age from 21 to 74 years $(M=35.45, S D=11.15)$. Participants were compensated with US $\$ 0.70$. A sensitivity analysis conducted using $G *$ power suggested that with $\alpha=0.05$ and $1-\beta=0.80$ power, the sample of 201 participants would be sufficient to detect a correlation of at least $r=0.12$.

\subsubsection{Procedure and measured variables}

After signing the consent form, participants completed an eligibility questionnaire that asked them to indicate whether they are an American citizen ("Are you an American citizen?"), if they reside in the United States ("Do you reside in the United States?"), and whether they identified as a Christian ("Do you identity as a Christian?"). They were then asked to complete an array of questionnaires, including items that assessed collective nostalgia for an open society, collective nostalgia for a homogeneous society, anti-immigration sentiments and blatant prejudice against Muslims living in the United States. All items were anchored at 1 (strongly disagree) and 7 (strongly agree), unless stated otherwise. Thereafter, participants completed various questions asking for demographic information (e.g., age, sex).

\subsubsection{Collective nostalgia for an open society}

We designed three items ( $\alpha=0.79$ ) that assessed collective nostalgia for an open society. These items were: "I feel nostalgia for a time when America was more open to cultural and religious diversity," "I am not nostalgic for an America that was more permitting of cultural and religious diversity" (reverse-scored), "I long for a time when America was more accepting of all people of all cultures or religions." Higher average scores indicate greater collective nostalgia for an open society.

\subsubsection{Collective nostalgia for a homogeneous society}

We designed three items $(\alpha=0.79)$ that assessed collective nostalgia for a homogenous society. These items were: "I feel nostalgic for a time when America was more homogeneous (i.e., the same) in terms of cultural and religious beliefs," "I long for a time when Americans were more culturally and religiously similar," and "I am not nostalgic for an America where people were more similar in terms of their culture and religion" (reverse-scored). Higher average scores indicate greater collective nostalgia for a homogenous society.

\subsubsection{Anti-immigration sentiments}

Five items ( $\alpha=0.88)$ were created to assess attitudes about immigration. The first two items were anchored at 1 (too few) to 7 (too many). These items were: "The number of immigrants the US government is allowing into our country is...," and "The number of refugees the US government is allowing into our country is..." The last three items were anchored at 1 (strongly disagree) and 7 (strongly agree). These items were: "I am opposed to immigration reform that enables currently 
undocumented immigrants a path to citizenship," "America doesn't need to give citizenship to currently undocumented immigrants," and "I think there is a need for immigration reform that allows undocumented immigrants a path to citizenship" (reverse-scored). Higher average scores indicate greater opposition to immigration.

\subsubsection{Blatant prejudice against Muslims in America}

Ten items were constructed for the current research to assess blatant prejudicial attitudes and support for discriminatory behavior towards Muslims living in the United States $(\alpha=0.92)$, e.g., "I support forcing Muslims to take specific courses on Western values." Higher average scores indicate more negative attitudes towards Muslims.

\subsection{Results}

\subsubsection{Confirmatory factor analysis}

Two independent sets of confirmatory factor analyses (CFA) were performed using AMOS 26 software $^{1}$ to determine whether (a) the items assessing the two hypothesized types of collective nostalgia and (b) the items assessing prejudice against Muslim Americans and anti-immigration sentiments loaded onto different and reliable factors. In particular, we tested whether two-factor models with latent variables fit the data better than a one-factor models in which all the items were collapsed into one latent variable.

We found that even though all collective nostalgia items loaded strongly on their respective latent factor (all standardized loadings above 0.50 are significant), the two-factor solution (Model 1a) had a moderate fit to the data (see Table 1 for model fit indices). The modification indices suggested that the model fit could be improved by adding a correlation between the error terms of the reverse coded items of the two collective nostalgia scales. This is not surprising given both items are phrased in terms of not feeling nostalgia. In other words, it indicates that people who are not feeling any kind of collective nostalgia scored low on both items and that they therefore measure something in common (i.e., not being nostalgic about any aspect of the collective past) other than the two latent variables in the model. We therefore added a correlation between the error terms of these items, which resulted in good model fit (Model 1b). This model had a better fit than both alternative one-factor models (Models $2 \mathrm{a}$ and $2 \mathrm{~b}$ in Table 1 ), which suggests that openness-focused and homogeneity-focused nostalgia are empirically distinct. Even though the two reverse coded items of the separate scales were correlated, they both had a high and significant factor loading on their respective latent variable and can hence be seen as suitable items for measuring nostalgia for an open and for a homogenous society.

For the blatant prejudice against Muslim Americans and anti-immigrant sentiments measures, we found that regardless of whether we allowed error terms to correlate both single factor and two-factor models (see Table 2, Models 1a, 1b, 2a, 2b) had an unsatisfactory fit to the data. Examination of the standardized factor loadings revealed that all reverse scored items of the blatant prejudice against Muslim Americans measure had low factor loadings (between 0.26 and 0.48 ; average loading of 0.38 ). We therefore tested both the single and twofactor solutions in which these items were excluded. The two-factor model (Model 3a) yielded a better, but still unacceptable fit. Inspection of the modification indices revealed that the fit could be improved by allowing three correlations between error terms of items measuring similar aspects of attitudes (i.e., items 6 and 7 of the blatant prejudice against Muslim Americans scale, between items 2 and 3, and items 4 and 5 of the anti-immigrant sentiments scale). Adding these

\footnotetext{
${ }^{1}$ Because AMOS 26 cannot handle missing data (we detected between 1.5 and $4 \%$ missingness, depending on the item), we created a correlation matrix that was used as input for all analyses. This procedure was used for all CFA analyses reported in this article.
}

correlations resulted in a good model fit (Model 3b). This two-factor model was also a better fit than the tested single-factor models (Models $4 \mathrm{a}$ and $4 \mathrm{~b}$ ) in which the reverse-scored items were excluded. This indicates that the reduced scale of blatant prejudice against Muslim Americans (based on 6 instead of the original 10 items) and the scale for anti-immigrant sentiments are distinct constructs. Based on these results we decided to use the reduced form scale of prejudice against Muslim Americans in all subsequent analyses.

\subsubsection{Mean scores and intercorrelations}

Mean scores and correlations among the two collective nostalgia measures, anti-Muslim, and anti-immigration attitudes are presented in Table 3.

There was no association between collective nostalgia for a homogeneous society and collective nostalgia for an open society. Collective nostalgia for an open society was negatively related to anti-immigration attitudes and blatant anti-Muslim prejudice. Conversely, collective nostalgia for a homogenous society showed a positive correlation with both of these measures. This provides preliminary support for our prediction that collective nostalgia for an open society is associated with positive attitudes towards immigrant out-groups, whereas this association is reversed for people longing for a more homogeneous national past. Finally, anti-immigrant and anti-Muslim attitudes were quite strongly and positively related.

The mean score for openness-focused nostalgia was significantly above the neutral midpoint of the scale, $t(196)=6.95, p<.001$, $d=0.49$, indicating that overall participants reported relatively high levels of collective nostalgia for a more open society. The mean score for homogeneity-focused collective nostalgia was around the neutral midpoint of the scale, $t(197)=-1.53, p=.128, d=-0.11$, indicating participants were relatively neutral in their collective nostalgia for a more homogeneous society. Regarding anti-immigration attitudes, the mean score was at the neutral midpoint of the scale, $t$ $(193)=0.472, p=.637, d=0.03$, which suggests that participants were relatively neutral in their attitudes towards immigration. For blatant anti-Muslim prejudice, the mean score was significantly below the neutral midpoint of the scale, $t(195)=-14.77, p<.001$, $d=-1.05$, which suggests participants were relatively low in their support for this extreme form of anti-Muslim attitudes.

\subsubsection{Regression analyses}

Lastly, to test the relative importance of openness- and homogeneity-focused collective nostalgia in predicting anti-immigrant and anti-Muslim attitudes, we conducted two analyses of hierarchical linear regression, using OLS regression in SPSS. For more robust results we included participants' age, gender (coded 0 for women and 1 for men), and their political orientation (where $1=$ strongly liberal and 7 = strongly conservative) as predictors in the first step, followed by both types of nostalgia in the second step (see Table 4).

As predicted, collective nostalgia for a more open society was a significant and negative predictor of anti-immigrant and blatant antiMuslim attitudes. This effect was significant above and beyond the effects of demographic variables and participants' political orientation. Conversely, collective nostalgia for a more homogenous society was a significant positive predictor of both types of hostile intergroup attitudes.

\subsection{Discussion}

The results of Study 1 confirmed our general hypothesis that members of a given group can nostalgize about very different aspects of collective past. Moreover, prejudice towards immigrants and outgroups are related to the content of the collective nostalgia a group member experiences. We showed that American Christians can experience at least two unique (i.e., differentiable) types of collective nostalgia: collective nostalgia for a time when American society was 
Table 1

Fit indices for the confirmatory factor analysis of nostalgia for an open society and nostalgia for a homogenous society measures in Studies $1 \mathrm{a}, 1 \mathrm{~b}$, and 3 .

\begin{tabular}{|c|c|c|c|c|c|}
\hline Study & Model & $\chi^{2}(\mathrm{df})$ & CFI & RMSEA & SRMR \\
\hline \multirow[t]{4}{*}{ Study 1a } & Model 1a: Two latent factors & 47.37(8), $p<.001$ & 0.912 & 0.158 & 0.074 \\
\hline & Model 1b: Two latent factors \& error correlation & $11.42(7), p=.121$ & 0.990 & 0.057 & 0.043 \\
\hline & Model 2a: One latent factor & 261.45(9), $p<.001$ & 0.433 & 0.377 & 0.223 \\
\hline & Model 2b: One latent factor \& error correlation & $238.37(8), p<.001$ & 0.482 & 0.382 & 0.211 \\
\hline \multirow[t]{2}{*}{ Study $1 \mathrm{~b}$} & Model 1: Two latent factors & $2.23(1), p=.135$ & 1.000 & 0.032 & 0.003 \\
\hline & Model 2: One latent factor & $919.95(2), p<.001$ & 0.683 & 0.623 & 0.162 \\
\hline \multirow[t]{3}{*}{ Study 3} & Model 1: Two latent factors & $14.95(8), p=.001$ & 0.992 & 0.048 & 0.030 \\
\hline & Model 2a: One latent factor & $319.19(9), p<.001$ & 0.655 & 0.303 & 0.151 \\
\hline & Model 2b: One latent factor \& error correlation & 25.78(7), $p=.001$ & 0.979 & 0.085 & 0.053 \\
\hline
\end{tabular}

Table 2

Fit indices for the confirmatory factor analysis of blatant prejudice against Muslims in America and anti-immigrant sentiments measures in Studies 1 a, 2 , and 3.

\begin{tabular}{|c|c|c|c|c|c|}
\hline Study & Model & $\chi^{2}(\mathrm{df})$ & CFI & RMSEA & SRMR \\
\hline \multirow[t]{8}{*}{ Study 1a } & Model 1a: Single latent factor & 1149.07(90), $p<.001$ & 0.522 & 0.246 & 0.179 \\
\hline & Model 1b: Single latent factor (allowing error correlation) & 413.42(82), $p<.001$ & 0.850 & 0.144 & 0.151 \\
\hline & Model 2a: Two latent factors & $800.06(89), p<.001$ & 0.679 & 0.202 & 0.175 \\
\hline & Model 2b: Two latent factors (allowing error correlation) & $411.72(84), p<.001$ & 0.852 & 0.141 & 0.147 \\
\hline & Model 3a: Two latent factor (reverse-scored items excluded) & $228.04(43), p<.001$ & 0.884 & 0.149 & 0.089 \\
\hline & Model 3b: Two latent factors (reverse-scored items excluded \& allowing error correlation) & 92.35(39), $p<.001$ & 0.967 & 0.084 & 0.060 \\
\hline & Model 4a: One latent factor (reverse-scored items excluded) & $610.45(44), p<.001$ & 0.645 & 0.257 & 0.176 \\
\hline & Model 4b: One latent factor (reverse-scored items excluded \& allowing error correlation & 171.56(39), $p<.001$ & 0.917 & 0.132 & 0.137 \\
\hline \multirow[t]{8}{*}{ Study 2} & Model 1a: Single latent factor & 1706.09(90), $p<.001$ & 0.540 & 0.232 & 0.161 \\
\hline & Model 1b: Single latent factor (allowing error correlation) & 455.87(82), $p<.001$ & 0.894 & 0.117 & 0.127 \\
\hline & Model 2a: Two latent factors & $1080.50(89), p<.001$ & 0.718 & 0.183 & 0.130 \\
\hline & Model 2b: Two latent factors (allowing error correlation) & $368.26(84), p<.001$ & 0.919 & 0.101 & 0.104 \\
\hline & Model 3a: Two latent factor (reverse-scored items excluded) & 296.77(43), $p<.001$ & 0.900 & 0.133 & 0.056 \\
\hline & Model 3b: Two latent factors (reverse-scored items excluded \& allowing error correlation) & $144.53(42), p<.001$ & 0.960 & 0.086 & 0.050 \\
\hline & Model 4a: One latent factor (reverse-scored items excluded) & $971.70(44), p<.001$ & 0.636 & 0.252 & 0.173 \\
\hline & Model 4b: One latent factor (reverse-scored items excluded \& allowing error correlation & 205.41(37), $p<.001$ & 0.934 & 0.117 & 0.117 \\
\hline \multirow[t]{8}{*}{ Study 3} & Model 1a: Single latent factor & 1789.40(90), $p<.001$ & 0.580 & 0.224 & 0.141 \\
\hline & Model 1b: Single latent factor (allowing error correlation) & $954.10(84), p<.001$ & 0.785 & 0.166 & 0.122 \\
\hline & Model 2a: Two latent factors & 1291.10(89), $p<.001$ & 0.703 & 0.190 & 0.136 \\
\hline & Model 2b: Two latent factors (allowing error correlation) & $300.65(82), p<.001$ & 0.946 & 0.084 & 0.121 \\
\hline & Model 3a: Two latent factor (reverse-scored items excluded) & 253.80(43), $p<.001$ & 0.922 & 0.114 & 0.057 \\
\hline & Model 3b: Two latent factors (reverse-scored items excluded \& allowing error correlation) & $110.34(41), p<.001$ & 0.974 & 0.067 & 0.053 \\
\hline & Model 4a: One latent factor (reverse-scored items excluded) & $960.73(44), p<.001$ & 0.660 & 0.236 & 0.161 \\
\hline & Model 4b: One latent factor (reverse-scored items excluded \& allowing error correlation & 265.38(39), $p<.001$ & 0.916 & 0.124 & 0.118 \\
\hline
\end{tabular}

Table 3

Descriptive statistics and correlations among variables in Studies 1a and 1b.

\begin{tabular}{|c|c|c|c|c|c|c|}
\hline Variable & $M$ & $S D$ & 1 & 2 & 3 & 4 \\
\hline \multicolumn{7}{|l|}{ Study 1a } \\
\hline 1. Collective nostalgia for an open society & 4.65 & 1.31 & - & & & \\
\hline 2. Collective nostalgia for homogeneous society & 3.84 & 1.47 & 0.07 & - & & \\
\hline 3. Prejudice against Muslim Americans & 2.37 & 1.55 & $-0.28^{* * * *}$ & $0.29^{* * * * *}$ & - & \\
\hline 4. Anti-immigration sentiments & 4.05 & 1.49 & $-0.35^{* * * *}$ & $0.46^{* * * *}$ & $0.60^{* * * *}$ & - \\
\hline \multicolumn{7}{|l|}{ Study $1 b$} \\
\hline 1. Collective nostalgia for an open society & 3.29 & 1.31 & - & & & \\
\hline 2. Collective nostalgia for homogeneous society & 3.27 & 1.35 & $0.49^{\text {*:**: }}$ & - & & \\
\hline 3. Anti-immigration sentiments & 4.58 & 1.55 & $-0.21^{* * * *}$ & $0.11^{* * * *}$ & - & \\
\hline
\end{tabular}

*** $p<.001$.

more open to cultural and religious diversity and collective nostalgia for when America was a more homogeneous society. As predicted, there was a strong negative association between collective nostalgic reverie for a more open American society and anti-immigration sentiments as well as blatant prejudice against Muslim Americans. Conversely, those who reported feelings of collective nostalgic reverie for a more homogeneous American society also tended to report stronger anti-immigration sentiments and blatant prejudices towards Muslims. We also demonstrated that the two types of collective nostalgia are significant predictors of intergroup attitudes above and beyond participants' political views and their demographic characteristics (age and gender).

\section{Study $1 b$}

The aim of Study $1 \mathrm{~b}$ was to replicate the results of Study $1 \mathrm{a}$ in a different cultural context. To this effect, items measuring collective nostalgia for an open society and for a homogenous society were included into a larger, representative sample study on attitudes towards and engagement in collective action conducted in Poland. Despite the current ethnic homogeneity of Poland (95\% of the population identifies as ethnically Polish; Statistics Poland, January, 2013), historically Poland was an ethnically diverse country. Indeed, prior to World War II, approximately $36 \%$ of the Polish population was comprised of ethnic and religious minority groups (Eberhardt, 2006). This demographic 
Table 4

Two types of nostalgia as predictors of anti-Muslim and anti-immigrant attitudes in Study 1a.

\begin{tabular}{|c|c|c|c|c|c|c|}
\hline & \multicolumn{3}{|c|}{ DV: Anti-Muslim prejudice } & \multicolumn{3}{|c|}{ DV: Anti-immigrant prejudice } \\
\hline & $B$ & $\beta$ & $t$ & $B$ & $\beta$ & $t$ \\
\hline Age & -0.02 & -0.17 & $-2.36^{*}$ & 0.12 & 0.09 & 1.49 \\
\hline Sex & 0.59 & 0.19 & $2.73^{* *}$ & 0.11 & 0.04 & 0.61 \\
\hline Political orientation & 0.17 & 0.20 & $2.83^{* *}$ & 0.21 & 0.25 & $3.97^{* * * *}$ \\
\hline$\Delta \mathrm{R}^{2}$ & $0.10^{* * *}$ & & & $0.21^{* * * *}$ & & \\
\hline Openness nostalgia & -0.29 & -0.25 & $-3.63^{\text {**** }}$ & -0.30 & -0.27 & $-4.47^{\text {*****1}}$ \\
\hline Homogeneity nostalgia & 0.26 & 0.25 & $3.67^{* * *}$ & 0.37 & 0.37 & $6.07^{\text {***** }}$ \\
\hline$\Delta \mathrm{R}^{2}$ & $0.10^{* * *}$ & & & $0.19^{* * * *}$ & & \\
\hline $\mathrm{R}_{\text {adj }}^{2}$ & $0.19^{* * *}$ & & & $0.38^{* * *}$ & & \\
\hline
\end{tabular}

$* p<.05$.

*** $p<.01$.

*** $p<.001$.

change makes Poland an ideal context to study "longing for greater openness/diversity".

Similar to Study 1a, we expected that the two types of collective nostalgia constitute separate constructs, and that they produce a differential pattern of correlations with outgroup-directed attitudes. Specifically, we expected openness-focused nostalgia to be a negative predictor of hostile intergroup attitudes and homogeneity-focused nostalgia to be a positive predictor of such sentiments.

\subsection{Methods}

\subsubsection{Participants}

One thousand three-hundred Polish citizens participated in the study. They were randomly selected based on their national identification number to be representative of the Polish population. The study was conducted by a research company Danae (www.danae.com.pl) and used computer-assisted personal interview methodology. They recruited 698 women and 602 men, who ranged in age from 18 to 93 $(M=47.20 ; S D=16.18)$. A sensitivity analysis conducted using $G^{*}$ power suggested that with $\alpha=0.05$ and $1-\beta=0.80$ power, the sample of 1300 participants would be sufficient to detect a correlation of $r=0.05$.

\subsubsection{Procedure and measured variables}

After consenting to take part in the study, the participants were asked to provide answers to a questionnaire that focused primarily on their attitudes towards collective action and their embeddedness in social networks conducive to social activism. Due to space constraints, we used abbreviated versions of the collective nostalgia measures and only a single-item measure of intergroup attitudes. In particular, we only used two positively worded nostalgia items per nostalgia sub-scale and one item to measure participants' attitudes towards immigration. Participants were also asked several demographic questions (age, gender, political orientation).

\subsubsection{Collective nostalgia for an open society}

Two items, $r(1173)=0.82, p<.001$, assessed collective nostalgia for an open society. These items were: "I feel nostalgia for a time when Poland was more open to cultural diversity" and "I long for a time when Poland was more accepting of all people of all cultures". To match the rest of the questionnaire, response options were anchored at 1 (strongly disagree) and 6 (strongly agree). Higher average scores indicate greater collective nostalgia for an open society.

\subsubsection{Collective nostalgia for a homogeneous society}

Two items measured nostalgia for a homogenous society, $r$ $(1162)=0.80, p<.001$. These items were: "I feel nostalgic for a time when Poland was more homogeneous (i.e., the same) in terms of culture" and "I long for a time when Poles were more culturally similar".
Response options were anchored at 1 (strongly disagree) and 6 (strongly agree). Higher average scores indicate greater collective nostalgia for a homogeneous society.

\subsubsection{Anti-immigration sentiments}

A single item was used to assess anti-immigration sentiments. This item was: "What do you think about the number of immigrants coming to Poland?". Response options were anchored at 1 (I think the number of immigrants should be reduced), 4 (I think the number of immigrants should stay as it is), and 7 (I think the number of immigrants should be increased).

\subsection{Results}

\subsubsection{Confirmatory factor analysis}

To replicate the distinction between nostalgia for an open society and nostalgia for a homogenous society found in Study 1a, we conducted a confirmatory factor analysis using AMOS 26 software. Similar to the previous study, we tested whether a two-factor model with latent variables fit the data better than a one-factor model in which all the items were collapsed into one latent variable.

As expected, a 2 -factor model fit the data well, while a 1 -factor model did not (see Table 1). As we did not include reverse-scored items in this study, there was no need to correlate error terms. The two items measuring each of the collective nostalgia types were averaged to create composite scores.

\subsubsection{Mean scores and intercorrelations}

Mean scores and correlations among the collective nostalgia measures and anti-immigration attitudes are shown in Table 3.

Nostalgia for an open society was negatively related to hostile attitudes towards immigrants, whereas nostalgia for a homogenous society correlated positively with the measure of anti-immigrant sentiment. Interestingly, the two types of collective nostalgia measured in Study $1 \mathrm{~b}$ turned out to be significantly and positively related, that is, the more a given participant experienced openness-focused nostalgia, the more likely they were to also report homogeneity-focused nostalgia.

The mean scores for both types of collective nostalgia were significantly below the neutral midpoint of the scale, $t(1231)=-5.69$, $p<.001, d=-0.16$ for openness-focused nostalgia and $t$ (1208) $=-5.99, p<.001, d=-0.17$ for homogeneity-focused nostalgia. Poles also displayed rather hostile attitudes towards immigrants, with the mean score of anti-immigrant attitudes being significantly above the neutral mid-point of the scale, $t(1255)=13.25$, $p<.001, d=0.37$.

\subsubsection{Regression analysis}

We conducted a hierarchical linear regression using OLS regression in SPSS. Demographic variables (age, gender, and political orientation) were entered in the first step and the two types of collective nostalgia in 
Table 5

Two types of nostalgia as predictors of anti-immigrant attitudes in Study 1b. DV: Anti-immigrant prejudice

\begin{tabular}{lccc}
\cline { 2 - 4 } & $B$ & $\beta$ & $t$ \\
\hline Age & 0.01 & 0.09 & $2.41^{*}$ \\
Sex & 0.09 & 0.09 & 0.79 \\
Political orientation & 0.22 & 0.06 & 1.73 \\
$\Delta \mathrm{R}^{2}$ & $0.03^{* * *}$ & & \\
Openness nostalgia & -0.45 & -0.36 & $-8.93^{* * *}$ \\
Homogeneity nostalgia & 0.30 & 0.25 & $5.94^{* * *}$ \\
$\Delta \mathrm{R}^{2}$ & $0.10^{* * *}$ & & \\
$\mathrm{R}_{\text {adj }}^{2}$ & $0.13^{* * *}$ & & \\
\hline
\end{tabular}

$* p<.05$.

*** $p<.001$.

the second step (see Table 5). As predicted, nostalgia for a more open society was a significant and negative predictor of anti-immigrant attitudes. This effect was significant above and beyond the effects of demographic variables and participants' political orientation. On the other hand, nostalgia for a more homogenous society was a significant positive predictor of hostile intergroup attitudes.

\subsection{Discussion}

Study $1 \mathrm{~b}$ replicated the results of Study $1 \mathrm{a}$ in a different cultural context, using a representative sample of Polish citizens interviewed in their homes. As in Study 1a, openness- and homogeneity-focused collective nostalgia constitute two different constructs. Moreover, as predicted, they show a differential pattern of relations with intergroup attitudes. Namely, Poles who reported higher levels of openness-focused nostalgia were more accepting of immigrants, while those who reported higher levels of homogeneity-focused nostalgia were more hostile towards immigrants.

Unexpectedly, there was a positive association between opennessand homogeneity-focused nostalgia in Study 1b. This suggests that Polish participants can experience both group-based emotions simultaneously. A possible explanation may be that when nostalgizing about past homogeneity and openness, our Polish participants think about different target groups. Specifically, they may long for a homogenous society that was free of recent immigrants (immigration from Ukraine has significantly increased in recent years), whilst also longing for a time when Poland was more tolerant towards diversity (but this may be restricted to the more established minorities within Polish society and not newcomers). However, at present, this explanation is purely speculative. Research that is designed to specifically assess the observed positive association between homogeneity-focused and openness-focused nostalgia among Poles is warranted. It would also be of import to assess whether this positive association exists in other cultural, ethnic, national, or religious groups. A limitation of Study $1 \mathrm{~b}$ should also be noted. Specifically, a single item measure of anti-immigration sentiments. Simple item measures are notoriously unreliable. However, as previously noted, data for Study $1 \mathrm{~b}$ was collected as part of a larger survey on which we were allowed to piggyback only a few items. To capture all the constructs of interest, we only had room for a single item that assessed anti-immigration sentiments. We addressed this limitation in Studies 2 and 3 by returning to the multi-item measure used in Study 1a.

\section{Study 2}

The importance of Studies 1a and 1b lay in their treatment of collective nostalgia. Specifically, whilst previous research on this groupbased emotion has treated the content of the collective nostalgia experienced as noise, we demonstrated that there is utility in the signal provided by content of the nostalgic reverie and that not all nostalgia is related to greater intergroup hostility. However, both Studies 1a and 1b used a correlational design, thus hampering our ability to make causal inferences. The purpose of Study 2 was to assess whether priming people to feel collective nostalgia for a particular aspect of the ingroup's past-a more open or more homogeneous society - affects their intergroup attitudes.

We hypothesized that those who are primed to feel collective nostalgia for a time when American society was more open would report reduced anti-immigration sentiments relative to a control condition (i.e., an ordinary day in America's past) and also report decreased blatant prejudice against Muslim Americans. Conversely, those primed to feel collective nostalgia for a more homogeneous America should report increased anti-immigration sentiments and more blatant prejudice against Muslim Americans relative to those on the control condition.

\subsection{Method}

\subsubsection{Participants}

Five-hundred sixty-six MTurk workers participated in the experimental Study 2. The call for participants noted that participation was restricted to American citizens residing in the United States who identify as Christian. All participants reported being Christian. They were compensated with US $\$ 0.70$. The participants were asked to describe a specific type of a nostalgic event or an event from recent American past as part of the experimental manipulation. Their answers were treated as a manipulation check and coded by two independent coders $(\kappa=0.797 ; p<.001)$. Those participants who did not provide any answer, provided answers completely unrelated to the prompt or answers that indicated that they did not experience the type of nostalgia that they were primed with $(n=230)$ were excluded from the analyses leaving a final sample of 336 participants. ${ }^{2}$ All analyses reported below are for the truncated sample in which participants ranged in age from 19 to 78 years $(M=37.57, S D=12.10)$. One hundred thirty-five identified as men, 197 as women, one person identified as "Other" and three people did not provide information about gender. A sensitivity analysis conducted using $\mathrm{G}^{*}$ power suggested that with $\alpha=0.05$ and 1$\beta=0.80$ power, the sample of 336 participants would be sufficient to detect an effect size of $f=0.17$, corresponding to $\eta_{\mathrm{p}}{ }^{2}=0.03$ ).

\subsubsection{Procedure and measured variables}

Participants were randomly assigned to one of three conditions. In the collective nostalgia for an open society condition, participants read:

"Trump's policies have led Americans to talk about a time when America was an open society for those of all cultures or religious beliefs. Some Americans sentimentally long for an America that was more open to cultural and religious diversity. That is, they feel nostalgic for a more 'open' America of the past."

In the collective nostalgia for a homogeneous society, participants read:

"Trump's policies have led Americans to talk about a time when America was more homogeneous (i.e., the same) in terms of culture

\footnotetext{
${ }^{2}$ This pre-registered exclusion was based on criterion previously used in experiments that assessed the effects of personal nostalgia by Kim and Wohl (2015) as well as Wohl et al. (2018). Additionally, results of Studies 1a and 1b suggest that the two types of collective nostalgia are not only differentiable, they are not negatively correlated. Put another way, participants can nostalgize about both a more open society and a more homogeneous society, and thus for most participants, it should be possible to bring one of the two types of collective nostalgia to the fore via priming. For the results of ANOVAs where the validity of the participants' response to the open-end manipulation check in Studies 2 and 3 was entered as an additional between-participants factor see the Supplementary Materials (Appendices I and II)
} 
and religious belief. Some Americans sentimentally long for an America that had less cultural and religious diversity. That is, they feel nostalgic for a more homogeneous America of the past."

In the control condition, designed to prime ingroup's past without referring to any specific content or to nostalgic feelings, participants read:

"Please think of an ordinary event in America's past that took place in the last year. Try to bring this event to mind and think it through as though you were an observer of the event, rather than directly involved. Imagine the event as though you were a historian recording factual details."

In both experimental conditions, participants were provided with a definition of nostalgia ("a sentimental longing for the past") and asked to write about a period or event from America's past that makes them feel nostalgic for when America was "more open to cultural or religious diversity" (in the openness-nostalgia condition) or "more culturally and religiously homogeneous" (in the homogeneity-nostalgia condition). Participants in the control condition were asked to write "a purely factual and detailed account" of an everyday event in America's past.

After the priming and writing task, participants completed the measures assessing anti-immigration sentiments $(\alpha=0.89)$ and support for blatant prejudice against Muslims Americans $(\alpha=0.91)$, identical to the ones used in Study 1a. They were then debriefed about the nature of the study as well as the methodological need for the deception. Thereafter, participants were asked for consent to use their data in light of the deception. All participants agreed to let us use their data.

Similar to Study 1a, we conducted a series of confirmatory factor analyses to determine whether our dependent variables constitute separate dimensions. The results mirrored those found previously-a twofactor model without the reverse-scored items in which error terms were allowed to correlate provided the best fit to the data (model 3b; see Table 2 for all model fit indices).

\subsection{Results}

Means and standard deviations of both dependent variables in the experimental and control groups are presented in Table 6 .

To verify the hypothesis that people may be primed with different types of collective nostalgia, we conducted two one-way ANOVAs where the two types of intergroup attitudes were entered as separate dependent variables and the experimental condition as the betweenparticipants factor. The experimental condition had a significant effect on participants' attitudes towards immigration, $F(1,328)=3.83$, $p=.023, \eta_{\mathrm{p}}{ }^{2}=0.02$. Post-hoc analyses using the Bonferroni correction revealed that participants in the openness-nostalgia condition had significantly more positive attitudes towards immigrants than participants in the control condition $(p=.021)$, no other differences were significant. Additionally, including political orientation as a covariate rendered the effect of experimental condition marginally significant, $F$

Table 6

Means and standard deviations of dependent variables in Study 2.

\begin{tabular}{llll}
\hline & $\begin{array}{l}\text { Openness- } \\
\text { nostalgia }\end{array}$ & $\begin{array}{l}\text { Homogeneity- } \\
\text { nostalgia }\end{array}$ & Control \\
\cline { 2 - 4 } & $M(S D)$ & $M(S D)$ & $M(S D)$ \\
\hline $\begin{array}{c}\text { 1. Prejudice against } \\
\text { Muslim Americans }\end{array}$ & $1.75(1.22)$ & $2.03(1.42)$ & $1.92(1.30)$ \\
$\begin{array}{c}\text { 2. Anti-immigration } \\
\text { sentiments }\end{array}$ & $3.45^{\mathrm{a}}(1.70)$ & $3.88(1.55)$ & $4.00^{\mathrm{a}}(1.53)$ \\
\hline
\end{tabular}

Note. Means sharing superscripts in each row are different at $p<.05$.
$(1,325)=2.80, p=.062, \eta_{\mathrm{p}}{ }^{2}=0.02$. The effect of the experimental condition on blatant prejudice against Muslims was not significant, $F$ $(1,333)=1.11, p=.331, \eta_{\mathrm{p}}{ }^{2}=0.01$, inclusion of political orientation as a covariate did not change this result, $F(1,327)=0.370, p=.691$, $\eta_{\mathrm{p}}{ }^{2}=0.002$.

\subsection{Discussion}

Study 2 provided directional support for our general hypothesis that the content of collective nostalgia is an important determinant of group members' attitudes towards immigrant out-groups, and that group members can be induced to feel different kinds of collective nostalgia. Participants who were primed with nostalgia for an open society were significantly less likely to report anti-immigration sentiments than those in the control condition; participants in the homogeneity and control conditions did not differ from each another. However, these effects decreased to a level of marginal significance when political orientation was included as a covariate.

These results suggest that whilst priming collective nostalgia for an open society has the potential to trigger more positive attitudes towards immigration, priming collective nostalgia for a more homogeneous society does not necessarily result in more hostile intergroup sentiments, however, given the marginal significance of these results when political orientation was included in the analysis we remain cautious in interpreting them. Contrary to our expectations, the collective nostalgia manipulation did not have an effect on blatant prejudice towards Muslims. One possible explanation is that the level of blatant prejudice against Muslim Americans was generally low and there was not a lot of variability in it. Thus, it could have been difficult to move participants in the openness-condition to become even less prejudiced. Another possible reason for the relatively weak, though promising, effects found in Study 2 lay in the nature of our experimental manipulation. We wanted to evoke the current political climate and thus referred to Donald Trump in both of the experimental conditions. However, we did not do the same in the control condition, which may have introduced an unnecessary confound. Additionally, referencing Donald Trump may have also made the role of participants' political orientation more relevant to their reported attitudes (as evidenced by the effect of the manipulation being significantly decreased once political orientation was included in the analysis). Given the rather small effects, we wanted to address this shortcoming in another study.

\section{Study 3}

In Study 3, we sought to replicate and extend the results of Studies $1 \mathrm{a}, 1 \mathrm{~b}$, and 2 in two important ways. First, we wanted to use a clearer manipulation of collective nostalgia. To do so, we removed all references to Donald Trump from the experimental materials and changed the nature of the control condition in such a way as to elicit personal nostalgia (which was previously used as control in other collective nostalgia studies, e.g., Wildschut et al., 2014). Second, to emphasize the move from exploratory to confirmatory stage of our research, Study 3 was preregistered on Open Science Framework (for all pre-registration materials see: https://osf.io/ksge4/). Additionally, we included measures of openness-focused and homogeneity-focused collective nostalgia at the end of the study to explore whether the experimental manipulation would exert an effect on these feelings and whether this could help explain the effects found on our main dependent variables.

\subsection{Method}

\subsubsection{Participants}

Eight hundred and eleven Mturk workers participated in Study 3. The call for participants noted that participation was restricted to American citizens residing in the United States who identify as Christian. All participants reported being Christian. They received US 
$\$ 0.70$ for participating. As in Study 2, the participants were asked to describe a specific type of a nostalgic event (collective or personal). Their answers were treated as a manipulation check and coded by two independent coders $(\kappa=0.684)$. As in Study 2 and as indicated in our pre-registration documents, the participants whose answers did not reflect the kind of nostalgia that was primed $(n=422)$ were excluded from the analyses. Additionally, in light of the recent concerns about the use of VPS on Mturk (e.g., Kennedy et al., 2018), we collected participants' IP addresses and used the "rIP" R package (Kennedy et al., 2019) to determine whether any participants should be removed due their localization outside the U.S. and VPS likelihood. This analysis indicated that additional $n=13$ participants should be excluded leaving a final sample of $n=376$ participants $(149=$ men; $289=$ women). All analyses reported below are for the truncated sample in which participants ranged in age from 18 to 80 years $(M=37.55, S D=12.71)$. A sensitivity analysis conducted using $\mathrm{G}^{*}$ power suggested that with $\alpha=0.05$ and $1-\beta=0.80$ power, the sample of 376 participants would be sufficient to detect an effect size of $f=0.16$, corresponding to $\eta_{\mathrm{p}}{ }^{2}=0.03$ ).

\subsubsection{Procedure and measured variables}

The procedure and measures for Study 3 were identical to those in Study 2 with two important modifications of the experimental manipulation which was changed so that it: (1) did not include any references to Donald Trump and (2) used personal nostalgia (rather than a description of a past event) as a control condition (as in Wildschut et al., 2014). Participants were randomly assigned to one of three conditions. In all conditions, the participants were given a definition of "nostalgia" as "sentimental longing for the past". Thereafter, in the openness-focused nostalgia condition participants read:

"Rapid changes in the fabric of American society have led to widespread discussion about a time when America was more open (i.e., accepting) in terms other cultures and religious beliefs. Some Americans sentimentally long for an America that was more accepting of cultural and religious diversity. That is, they feel nostalgic for a more 'open' America of the past. Do you sometimes long for America's more open past? Please briefly write about a period or event from America's past that makes you feel nostalgic for when America was more open to (i.e., accepting of) cultural or religious diversity."

In the homogeneity-focused collective nostalgia condition participants read:

"Rapid changes in the fabric of American society have led to widespread discussion about a time when America was more homogeneous (i.e., the same) in terms of culture and religious belief. Some Americans sentimentally long for an America that had less cultural and religious diversity. That is, they feel nostalgic for a more homogeneous America of the past. Do you sometimes long for America's more homogeneous past? Please briefly write about a period or event from America's past that makes you feel nostalgic for when America was more culturally and religiously homogeneous (i.e., the same)."

\section{In the control condition participant read:}

"Rapid changes of the modern world have led many people to feel nostalgic about how things used to be in the past. Please think of an event in your personal life that makes you feel nostalgic and sentimental about how things in your life used to be. Please briefly write about this event from your own past that makes you feel nostalgic."

Following the experimental manipulation, the participants filled in the measures of anti-immigration sentiments $(\alpha=0.89)$ and support for blatant prejudice against Muslim Americans $(\alpha=0.91)$, identical to the ones used in Study 1a and Study 2. They also filled in the measure of collective nostalgia for an open society ( 3 items, $\alpha=0.80$ ) and collective nostalgia for a homogenous society ( 3 items, $\alpha=0.69$ ) that was used in Study 1a. ${ }^{3}$

Similar to Study 1a and Study 2, we conducted a series of confirmatory factor analyses to determine whether the collective nostalgia measure captured more than one dimension and whether the anti-immigration and prejudice again Muslims scales were separable. The results mirrored those found in all previous studies. Specifically, a twofactor model was the best fit for the collective nostalgia measures and did not even require any error correlations (see Table 1), while a one factor models - with or without correlated error terms - presented worse fit. Similarly, a two-factor model with correlated error terms provided the best fit to the data for our dependent variables (model 3b; see Table 2 for all model fit indices).

\subsection{Results}

Means, standard deviations, and correlations among both of the dependent variables and the measures of openness- and homogeneityfocused collective nostalgia in the experimental and control groups are presented in Table 7.

To verify the hypothesis that experimentally priming certain types of collective nostalgia will affect intergroup attitudes, we conducted two one-way ANOVAs where blatant prejudice against Muslims and anti-immigration sentiments were entered as separate dependent variables and experimental condition as a between-participants factor. The experimental condition had a significant effect on participants' attitudes towards immigration, $F(1,373)=3.70, p=.026, \eta_{\mathrm{p}}{ }^{2}=0.02$. Post-hoc analyses using the Bonferroni correction revealed that participants in the openness-nostalgia condition had significantly more positive attitudes towards immigrants than participants in the homogeneity-focused nostalgia condition, $p=.024$. No other differences were significant. Inclusion of participants' political orientation as a covariate rendered the effect of the experimental manipulation stronger, $F(1$, $370)=4.20, p=.016, \eta_{\mathrm{p}}{ }^{2}=0.02$, but did not change the pattern of results. In the model for blatant prejudice against Muslims, the assumption of variance homogeneity was not met, Levene's test: $F(2$, $371)=7.391, p<.001$. Therefore, we used the Kruskal-Wallis nonparametric test. Replicating the results of Study 2, the effect of the experimental manipulation on anti-Muslim prejudice was not significant, $H(2)=1.82, p=.403$.

We also conducted a mixed-design ANOVA for the two types of collective nostalgia as two levels of a within-participants factor and the experimental condition as the between-subjects factor. We found a significant main effect of the type of collective nostalgia, $F(1$, 373) $=92.25, p<.001, \eta_{\mathrm{p}}{ }^{2}=0.20$ with participants expressing significantly more openness-focused nostalgia than homogeneity-focused nostalgia $(p<.001)$. The effect of the experimental condition was also significant, $F(1,373)=10.32, p<.001, \eta_{\mathrm{p}}{ }^{2}=0.05$. The participants expressed more nostalgia when they were in the openness condition $(p=.001)$ or homogeneity condition $(p=.002)$ as compared to the control condition; the two experimental conditions did not differ from each other $(p=1.000)$. The interaction term was marginally significant, $F(1,373)=2.28, p=.103, \eta_{\mathrm{p}}{ }^{2}=0.01$. Analysis of simple effects showed that participants expressed significantly more opennessfocused nostalgia in the openness condition as compared to the control condition $(p=.001)$; the homogeneity condition did not differ from either the control $(p=.599)$ or the openness condition $(p=369)$. Participants also expressed significantly more homogeneity-focused nostalgia in the homogeneity condition as compared to the control

\footnotetext{
${ }^{3}$ Our pre-registration materials (https://osf.io/ksge4/) described a second hypothesis (i.e., we expected the nostalgia manipulation to impact participants' beliefs about nationhood) to be tested in Study 3. This idea will be examined in greater depth in a subsequent paper along with data already collected from a national representative sample of Dutch, and a study yet to be conducted.
} 
Table 7

Means, standard deviations, and correlations among variables used in Study 3.

\begin{tabular}{|c|c|c|c|c|c|c|}
\hline & Openness-nostalgia & Homogeneity-nostalgia & Control & & & \\
\hline & $M(S D)$ & $M(S D)$ & $M(S D)$ & 2. & 3. & 4. \\
\hline 1. Anti-Muslim prejudice & $1.69(0.97)$ & $1.87(1.23)$ & $2.00(1.45)$ & & & \\
\hline 2. Anti-immigration sentiments & $3.39^{\mathrm{a}}(1.65)$ & $4.08^{\mathrm{a}}(1.62)$ & $3.72(1.55)$ & $0.465^{\text {***** }}$ & & \\
\hline 3. Openness-focused nostalgia & $5.42^{\mathrm{a}}(1.07)$ & $5.10(1.31)$ & $4.86^{\mathrm{a}}(1.35)$ & $-0.321^{* * *}$ & $-0.461^{* * * * *}$ & \\
\hline 4. Homogeneity-focused nostalgia & $3.73(1.40)$ & $4.17^{\mathrm{a}}(1.63)$ & $3.59^{\mathrm{a}}(1.50)$ & $0.440^{* * *}$ & $0.598^{* * * *}$ & $-0.328^{* * * *}$ \\
\hline
\end{tabular}

Note. Means sharing superscripts in each row are different at $p<.05$.

*** $p<.001$.

condition $(p=.027)$, while participants in the openness condition did not differ from those in the control $(p=1.000)$ or the homogeneity condition ( $p=.224$ ) in terms of this type of collective nostalgia.

Lastly, we explored the potential indirect effects that our manipulation exerted on the two outcome variables via collective nostalgia for an open and homogenous society. To this end, we conducted two analyses of mediation (PROCESS 3.0, custom model; Hayes, 2018) where the experimental condition was entered as the independent variable, the two types of collective nostalgia as mediators, the two types of intergroup attitudes as two (separate) dependent variables, and political orientation was used as a covariate, predicting the dependent variable. Indicator coding was used for the multicategorical independent variable, whereby the openness condition was compared to the other two, and the homogeneity condition was compared to the other two; the control condition served as a reference group.

Participants in the openness condition expressed significantly more openness-focused nostalgia, $B=0.55, S E=0.15,95 \% \mathrm{CI}$ : $0.25,0.85$, but participants in the homogeneity condition did not, $B=0.24$, $S E=0.19,95 \%$ CI: $-0.13,0.61$. Conversely, participants in the homogeneity condition expressed significantly more homogeneity-focused nostalgia $B=0.58, S E=0.22$, 95\%CI: $0.15,1.02$, but participants in the openness condition did not, $B=0.17, S E=0.18,95 \% \mathrm{CI}$ : $-0.19,0.51$. Openness-focused nostalgia had a significant negative effect on blatant prejudice against Muslims, $B=-0.16, S E=0.05$, 95\%CI: $-0.26,-0.06$, while the effect of homogeneity-focused nostalgia was significant and positive, $B=0.31, S E=0.05,95 \%$ CI: 0.22 , 0.40 . Political orientation did not predict blatant anti-Muslim prejudice, $B=0.07, S E=0.04,95 \% \mathrm{CI}:-0.02,0.15$. There was a significant negative indirect effect of being assigned to the openness condition on blatant prejudice against Muslims via openness-focused nostalgia, $B=-0.09, S E=0.04$, 95\%CI: $-0.17,-0.02$, but not via homogeneity-focused nostalgia, $B=0.05, S E=0.05$, 95\%CI: $=-0.06$, 0.16 . There was also a significant positive indirect effect of being assigned to the homogeneity-focused condition on prejudice via homogeneity-focused nostalgia, $B=0.18, S E=0.08,95 \% \mathrm{CI}$ : $0.04,0.35$, but not via openness-focused nostalgia, $B=-0.04, S E=0.03$, 95\%CI: $-0.11,0.02$ (see Fig. 1).

In the model for anti-immigrant sentiments as dependent variable the relations between the independent variable and the two mediators were identical to the previous one. Openness-focused nostalgia was a significant negative predictor of anti-immigrant attitudes, $B=-0.25$, $S E=0.05$, 95\%CI: $-0.35,-0.16$, while homogeneity-focused nostalgia was a significant positive predictor, $B=0.38, S E=0.05$, 95\%CI: $0.28,0.47$. Being assigned to the openness condition had a negative indirect effect on anti-immigrant attitudes via openness-focused nostalgia, $B=-0.14, S E=0.05,95 \% \mathrm{CI}:-0.25,-0.06$, but the effect via homogeneity-focused nostalgia was not significant, $B=0.06$, $S E=0.06$, 95\%CI: $-0.06,0.19$. Conversely, being in the homogeneity condition exerted a positive indirect effect on anti-immigrant attitudes via homogeneity-nostalgia, $B=0.22, S E=0.10,95 \% \mathrm{CI}$ : 0.04, 0.42, but not via openness-nostalgia, $B=-0.06, S E=0.05$, 95\%CI: -0.17 , 0.04 (see Fig. 2).

\subsection{Discussion}

Study 3 replicated and extended the results found in Study 2. In particular, using an experimental manipulation without reference to Donald Trump and his political rhetoric, we showed that priming openness-focused collective nostalgia leads to a decrease in anti-immigrant sentiments (as compared to a control group in which participants were primed with personal nostalgia). Akin to Study 2, we did not find an effect for the measure of blatant anti-Muslim prejudice.

An additional exploratory analysis of indirect effects showed that both experimental conditions led to increases of the respective type of collective nostalgia that they aimed to prime, i.e., participants primed with nostalgia for a more homogenous society reported higher levels of homogeneity-focused nostalgia, while those primed with nostalgia for a more open society reported higher levels of openness-focused nostalgia. These stronger feelings of homogeneity-focused and openness-focused nostalgia, in turn, were related to (respectively) more negative and more positive intergroup attitudes (both in terms of attitudes towards immigrants and blatant attitudes towards Muslims). Having said that, it is noteworthy that only a marginally significant interaction between the experimental condition and the type of nostalgia was observed when analysing the data with a mixed-design ANOVA. This constitutes a limitation of the current research and points to the necessity of developing a stronger experimental manipulation for future studies.

\section{General discussion}

Collective nostalgic rhetoric has a long history of use as a political tool to fuel discontent among group members. The goal is to garner support to combat the processes (or people) perceived to be contributing to the decay of the ingroup's "true" form (Duyvendak, 2011; Gaston \& Hilhorst, 2018). To date, however, the extant literature on collective nostalgia has neglected the content of the collective nostalgia that group members may be experiencing, which may undermine its predictive utility. Indeed, even though members may agree on the group's charter (i.e., the most important events and figures that have contributed to the group's identity, e.g., World War II; Hilton \& Liu, 2008; Liu \& Hilton, 2005), social representations of the ingroup's history are likely varied (Moscovici, 1988), which may contribute to different aspects of the ingroup's past that members long to recover. Herein, we examined the heretofore untested idea that there is withingroup variance in the content of nostalgia group members experience, and this variance matters for understanding intergroup relations. Specifically, we tested for the presence of (and then primed) two types of collective nostalgia: reverie for a time when one's society was perceived to be more open to cultural and ethnic diversity, and reverie for a time when one's society was perceived to be more culturally and ethnically homogeneous. We tested whether the type of collective nostalgia experienced has implications for anti-immigration sentiments and blatant prejudice against Muslims.

Empirical support for our hypotheses was provided from two different socio-political intergroup contexts and four independent samples. In Study 1a, using a sample of Christian Americans, we found 


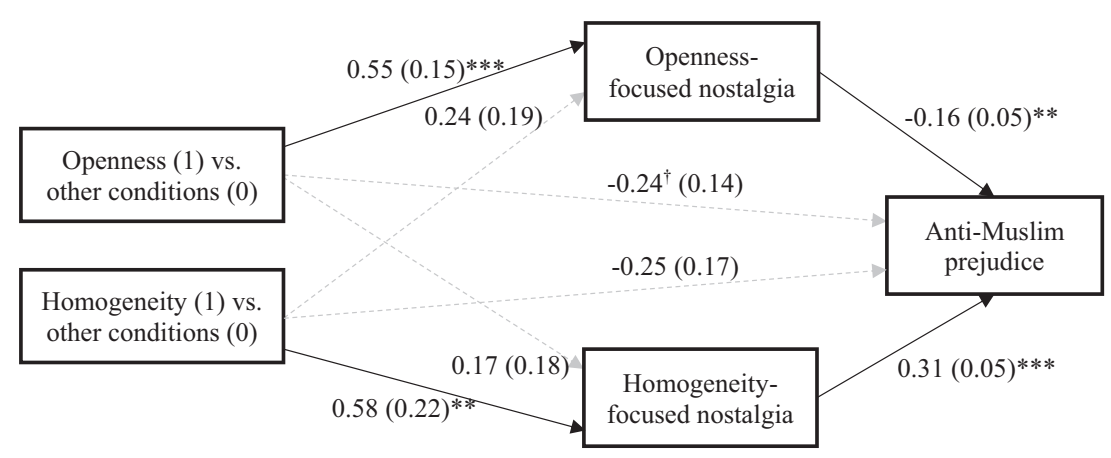

Bootstrap estimates $(95 \% \mathrm{CI})$ of indirect effects: Openness condition $\rightarrow$ Openness nostalgia $\rightarrow$ Prejudice: Openness condition $\rightarrow$ Homog. nostalgia $\rightarrow$ Prejudice: Homog. condition $\rightarrow$ Openness nostalgia $\rightarrow$ Prejudice: Homog. condition $\rightarrow$ Homog. nostalgia $\rightarrow$ Prejudice

$$
\begin{aligned}
& B=-0.09, S E=0.04(-0.17,-0.02) \\
& B=-0.05, S E=0.05(-0.05,0.16) \\
& B=-0.04, S E=0.03(-0.11,0.02) \\
& B=0.18, S E=0.08(0.03,0.35)
\end{aligned}
$$

Fig. 1. Indirect effects of the impact of the experimental manipulation on support for blatant anti-Muslim prejudice via openness- and homogeneity-focused nostalgia. Homog. = homogeneity.

$* * * p<.001 ; * *<.01 ;{ }^{\dagger} p<.09$.

evidence for the existence of at least two types of collective nostalgia: nostalgia for a past in which American society was more tolerant of other cultures and religions (collective nostalgia for an open society) and nostalgia for a past in which people in American society were more culturally and religiously similar (collective nostalgia for a homogeneous society). Importantly, we found a strong positive association between homogeneity-focused collective nostalgia and negative attitudes towards those perceived to have a different culture and hold different values (e.g., immigrants and Muslims in the Western world; see also Smeekes \& Verkuyten, 2013). Conversely, there was a strong negative correlation between openness-focused collective nostalgia and negative attitudes towards groups perceived to be culturally and religiously different. Put another way, group members who feel openness-focused collective nostalgia are more sympathetic towards and supportive of policies that demonstrate acceptance of outgroups as well as their beliefs or practices. This pattern of results was replicated in Study $1 \mathrm{~b}$ with a representative sample of native Poles interviewed at their homes. The more our Polish participants reported homogeneity-focused nostalgia the less accepting they were of immigrants coming to their country, while higher levels of openness-focused nostalgia correlated with greater acceptance of immigrants.

In Studies 2 and 3, we demonstrated that the content of the collective nostalgia that group members experience can be primed-something, arguably, that some politicians know implicitly-by highlighting collective past that was more open to all cultures or religious beliefs or more homogeneous in terms of culture and religious belief. Importantly, priming particular content of collective nostalgia had implications for attitudes towards those deemed culturally and

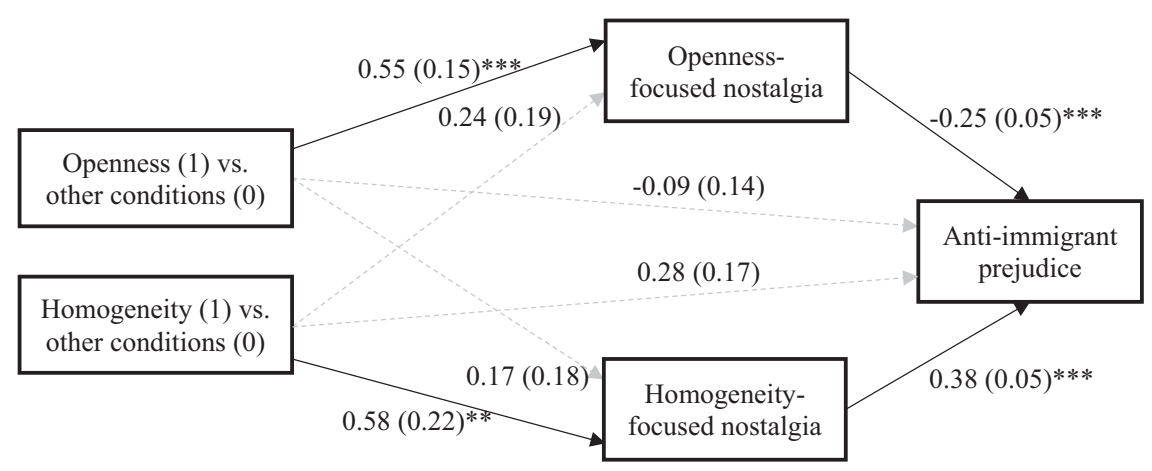

Bootstrap estimates $(95 \% \mathrm{CI})$ of indirect effects: Openness condition $\rightarrow$ Openness nostalgia $\rightarrow$ Prejudice: Openness condition $\rightarrow$ Homog. nostalgia $\rightarrow$ Prejudice: Homog. condition $\rightarrow$ Openness nostalgia $\rightarrow$ Prejudice: Homog. condition $\rightarrow$ Homog. nostalgia $\rightarrow$ Prejudice

$$
\begin{aligned}
& B=-0.14, S E=0.05(-0.25,-0.06) \\
& B=0.06, S E=0.06(-0.10,0.26) \\
& B=-0.06, S E=0.05(-0.17,0.04) \\
& B=0.22, S E=0.09(0.04,0.42)
\end{aligned}
$$

Fig. 2. Indirect effects of the impact of the experimental manipulation on support for anti-immigrant sentiments via openness- and homogeneity-focused nostalgia. Homog. $=$ homogeneity.

$* * * p<.001 ; * * 0<.01$. 
religiously different from the ingroup. In Study 3, Americans who were primed with nostalgia for an open society were significantly less likely to report anti-immigration sentiments compared to those manipulated to feel collective nostalgia for a homogeneous society. However, there was no difference between the collective nostalgia for a homogeneous American society and the control condition, thus suggesting that the baseline nostalgic reverie that Americans experience may in fact be oriented towards societal homogeneity. This possibility is further supported by the existing theory that sees collective nostalgia as the domain of conservatives (e.g., Lammers \& Baldwin, 2018). The added value of the current research is not only identifying that homogeneityfocused collective nostalgia might be the baseline type, but also that such nostalgizing can be experimentally altered by highlighting that American society used to be more open and tolerant.

Although openness-focused nostalgia was a significant and negative predictor of blatant prejudice towards Muslims and homogeneity-focused nostalgia was a significant positive predictor of such sentiments in our correlational studies, there were no between condition differences in blatant prejudice towards Muslim Americans in the two experiments. We believe that this result may be due to the fact that items in the blatant prejudice scale were particularly aggressive (e.g., "I support demolishing mosques in America"), and this may not have been palatable, regardless of the collective nostalgia experienced. This contention is supported by the generally low levels of support for this blatant measure in all of our samples (significantly below the mid-point of the scales used to assess it). A short experimental manipulation employed in the present research might not have been strong enough to influence such strong attitudes. It is also possible that when our participants were thinking about America's past openness to diversity, that openness did not necessarily include acceptance of Muslims. Indeed, historically acceptance of Muslims was considerably less present in American public discourse.

A set of two exploratory analyses of indirect effects conducted in Study 3 demonstrated, however, that although there was no direct effect of the experimental manipulation on blatant prejudice against Muslims, there was a significant indirect effect. Specifically, participants in the openness condition experienced greater openness-focused nostalgia which translated to lower blatant prejudice towards Muslims, while those in the homogeneity condition, felt more homogeneity-focused nostalgia and, in turn, displayed increased prejudice. An identical pattern of results was found for the measure of anti-immigrant sentiments. These results necessitate a controlled replication, but they do point to the possibility that it is indeed the difference in collective nostalgia that participants feel that shapes their intergroup attitudes.

\section{Implications}

The significance of this work is multi-fold. From a theoretical perspective, this research provides needed nuance to our understanding of the consequence(s) of collective nostalgia. The extant literature has yet to illuminate when and why collective nostalgia leads group members to pursue re-connection to the ingroup's past by constructive or destructive means. Instead, research has treated the content of collective nostalgic reflection as noise, which has stunted understanding of the group-based emotion. According to Lammers and Baldwin (2018), for example, collective nostalgia is an emotion experienced by those on the political right (i.e., conservatives). This understanding hinders the utility of collective nostalgia as a predictor of the ways members try to reclaim the ingroup's treasured past. Indeed, we showed that group members can and do nostalgize for a time when one's society was more tolerant of cultural and religious diversity-a sentiment that is more aligned with those on the political left (i.e., liberals).

From an applied societal perspective, the significance of the present findings lay in the perceived loss and change endemic in modernity (Boym, 2001; Davis, 1979), which has given rise to right-wing populism in Europe and North America (Mudde \& Kaltwasser, 2012). Right-wing populist leaders often use nostalgia-based slogans (e.g., "Make America Great Again" in the U.S. or "We want our country back" in Britain) as a tool to galvanize the electorate against those perceived to be causing this loss and change or discontinuity with the group's cherished past (e.g., immigrants; Mols \& Jetten, 2014). Critically, however, nostalgia can also be used constructively or pro-socially. For example, former American President Obama used nostalgia to advance the rights of immigrants in the name of "allegiance to our founding principles" (see Obama, 2013). Our research showed that those who experience collective nostalgia that is in line with Obama's sentiment are less apt to express anti-immigration sentiments and blatant prejudice against Muslims. Moreover, we showed that such nostalgizing can be experimentally heightened to yield such downstream pro-social intergroup effects.

\section{Limitations}

Some limitations of the current work should be noted. First, although the current research found evidence for two general types of collective nostalgia group members experience, openness and homogeneity are unlikely to be the only aspects of a group's past for which members experience sentimentally longing. Collective nostalgia is shaped by the ingroup's current (perceived) socio-political and cultural needs and is thus context-specific. When the needs of the group are frustrated or restricted, group members become motivated to fulfil those needs (see Kachanoff et al., in press). For instance, in post-communist countries (e.g., Poland and Russia), collective nostalgia for communism is high among those who did not fare well economically during political transformation (Prusik \& Lewicka, 2016; White, 2010). In a similar manner, under conditions that suggest the ingroup is losing international status, group members may sentimentally long for the days when their group held a more dominant position on the world stage.

Second, although we examined the role of collective nostalgia (for an open and for a homogenous society) as a mediator of the link between our experimental manipulation and outcomes of interest, we acknowledge the issues associated with this analysis. Specifically, the establishments of causation cannot be determined by an analysis of indirect effects on its own. To establish mediation or a causal indirect influence, the causal story requires methodological and conceptual justification (see Fiedler et al., 2018). In the current research, we made some steps in this direction via experimental manipulation. However, we did not empirically establish that the proposed mediator clearly causes the outcome variable rather than the other way around. That said, a logical argument can be made for the causal order under investigation (i.e., manipulation of collective nostalgia of a certain type causes that type of nostalgia). That said, it would behoove researchers to provide a clearer evidence of this causal link as well as other possible mechanisms responsible for the collective nostalgia-intergroup attitudes link such as perceptions of outgroups as endangering the collective continuity of the ingroup which will likely be heightened by homogeneity-focused nostalgia and lowered by openness-focused nostalgia.

\section{Conclusion}

Across three studies (including a high-power replication as well as a nationally representative sample), we found that collective nostalgia is not a monolithic construct-not all group members long for the same aspect of their ingroup's past. This variance matters. The content of the collective nostalgia group members experience has predictive utility in that it illuminates their attitudes towards outgroups and the policies they are willing to support. Moreover, the content of collective nostalgia can be primed. Taken together, these results support the notion that politicians can (and do) manipulate support for their goals by eliciting sentimental longings for a past (that may or may not have 
existed), which can have a significant influence on intergroup relations.

\section{Appendix A. Supplementary data}

Supplementary data to this article can be found online at https:// doi.org/10.1016/j.jesp.2020.104044.

\section{References}

Bar-Tal, D. (2007). Sociopsychological foundations of intractable conflicts. American Behavioral Scientist, 50, 1430-1453. https://doi.org/10.1177/0002764207302462. Blight, D. W. (2001). Race and Reunion. Belknap: London.

Boym, S. (2001). The future of nostalgia. New York, NY: Basic Books.

Bruneau, E., Kteily, N., \& Laustsen, L. (2018). The unique effects of blatant dehumanization on attitudes and behavior towards Muslim refugees during the European "refugee crisis" across four countries. European Journal of Social Psychology, 48(5), 645-662. https://doi.org/10.1002/ejsp.2357.

Byrne, B. (2007). England-whose England? Narratives of nostalgia, emptiness and evasion in imaginations of national identity. The Sociological Review, 55, 509-530. https://doi.org/10.1111/j.1467-954X.2007.00720.x.

Cernat, V. (2010). Socio-economic status and political support in post-communist Romania. Communist and Post-Communist Studies, 43, 43-50. https://doi.org/10. 1016/j.postcomstud.2010.01.001.

Cheung, W.-Y., Sedikides, C., Wildschut, T., Tausch, N., \& Ayanian, A. H. (2017). Collective nostalgia is associated with stronger outgroup-directed anger and participation in ingroup-favoring collective action. Journal of Social and Political Psychology, 5, 301-319. https://doi.org/10.5964/jspp.v5i2.697.

Davis, F. (1979). Yearning for yesterday: A sociology of nostalgia. New York, NY: Free Press.

de Vries, C. E., \& Hoffman, I. (2018). Globalization and European integration: Threat or opportunity? Perception, knowledge and policy preferences of European citizens. Eupinions. Retrieved from https://eupinions.eu/fileadmin/files/BSt/.../EZ eupinions 04_2017_englisch.pdf.

Dresler-Hawke, E. (2005). Reconstructing the past and attributing the responsibility for the holocaust. Social Behavior and Personality, 33, 133-148. https://doi.org/10.2224/ sbp.2005.33.2.133.

Duyvendak, J. W. (2011). The politics of home: Belonging and nostalgia in Western Europe and the United States. Hampshire, UK: Palgrave Macmillan.

Eberhardt, P. (2006). Przemiany struktury etnicznej ludności Polski w XX wieku [Population structure changes in 20th Century Poland]. Sprawy Narodowościowe, 28, 53-74.

Fiedler, K., Harris, C., \& Schott, M. (2018). Unwarranted inferences from statistical mediation tests-an analysis of articles published in 2015. Journal of Experimental Social Psychology, 75, 95-102. https://doi.org/10.1016/j.jesp.2017.11.008.

Gaston, S., \& Hilhorst, S. (2018). At home in one's past: Nostalgia as a cultural and political force in Britain. Demos: France and Germany. Retrieved from https://demos.co.uk/ project/nostalgia/.

Greven, T. (2016). The rise of right-wing populism in Europe and the United States. Retrieved from https://www.fesdc.org/fileadmin/user upload/publications/ RightwingPopulism.pdf.

Hayes, A. F. (2018). Introduction to mediation, moderation, and conditional process analysis: A regression-based approach (2nd ed.). New York, NY: Guilford Press.

Hilton, D. J. \& Liu, J. H. (2008). Culture and inter-group relations. The role of socia representations of history. In: R. Sorrentino \& S. Yamaguchi (Eds.) The handbook of motivation and cognition: The cultural context (pp. 343-368), Guilford, New York.

Jetten, J., \& Wohl, M. J. A. (2012). The past as a determinant of the present: Historical continuity, collective angst, and opposition to immigration. European Journal of Social Psychology, 42, 442-450. https://doi.org/10.1002/ejsp.865.

Kachanoff, F. J., Wohl, M. J. A., \& Taylor, D. M. (2020). Striking at the core: A unified framework of howcollective victimhood affects basic psychological needs for relatedness, competence and autonomy. In J. R. Vollhardt (Ed.). The social psychology of collective victimhood (pp. 380-398). Oxford, UK: Oxford University Press.

Kahn, D. T., Klar, Y., \& Roccas, S. (2017). For the sake of the eternal group: Perceiving the group as trans-generational and endurance of ingroup suffering. Personality and Social Psychology Bulletin, 43, 272-283. https://doi.org/10.1177/0146167216684123.

Kennedy, R., Clifford, S., Burleigh, T., Waggoner, P., \& Jewell, R. (2018). How Venezuela's economic crisis is undermining social science research - About everything. (The Washington Post).

Kennedy, R., Waggoner, P., Clifford, S., \& Rudis, B. (2019). rIP: Detects fraud in online surveys by tracing, scoring and visualizing IP addresses. $\mathrm{R}$ package version 1.2 .0

Kim, H. S., \& Wohl, M. J. A. (2015). The bright side of feeling disconnected with the past self: Self-discontinuity (via nostalgia) increases readiness to change unhealthy behaviors. Social Psychology and Personality Psychology Science, 6, 229-237. https://doi. org $/ 10.1177 / 1948550614549482$

Kteily, N., \& Bruneau, E. (2017). Backlash: The politics and real-world consequences of minority group dehumanization. Personality and Social Psychology Bulletin, 43(1), 87-104. https://doi.org/10.1177/0146167216675334.

Lammers, J., \& Baldwin, M. (2018). Past-focused temporal communication overcomes conservatives' resistance to liberal political ideas. Journal of Personality and Social Psychology, 114, 599-619. doi:10.1037/pspi0000121Liu, J. H., Goldstein-Hawes, R.,
Hilton, D. J., Huang, L. L., Gastardo-Conaco, C., Dresler-Hawke, E., ... \& Hiddka, Y. (2005). Social representations of events and people in world history across twelve cultures. Journal of Cross-Cultural Psychology, 36, 171-191. doi:10.1177/ 0022022104272900

Liu, J. H., \& Hilton, D. J. (2005). How the past weighs on the present: Social representations of history and their role in identity politics. British Journal of Social Psychology, 44, 537-556. https://doi.org/10.1348/014466605X27162.

Liu, J. H., Lawrence, B., Ward, C., \& Abraham, S. (2002). Social representations of history in Malaysia and Singapore: On the relationship between national and ethnic identity. Asian Journal of Social Psychology, 5, 3-20. https://doi.org/10.1111/1467-839X. 00091.

Mols, F., \& Jetten, J. (2014). No guts, no glory: How framing the collective past paves the way for anti-immigrant sentiments. International Journal of Intercultural Relations, 43, 74-86. https://doi.org/10.1016/j.ijintrel.2014.08.014.

Moscovici, S. (1988). Notes towards a description of social representations. European Journal of Social Psychology, 18, 211-250. https://doi.org/10.1002/ejsp. 2420180303.

Mudde, C., \& Kaltwasser, C. R. (Eds.). (2012). Populism in Europe and the Americas: Threat or corrective for democracy?. Cambridge, UK: Cambridge University Press.

Obama, B. (2013). Remarks by the President on comprehensive immigration reform [Transcript]. Retrieved from https://obamawhitehouse.archives.gov/the-press office/2013/01/29/remarks-president-comprehensive-immigration-reform.

Prusik, M., \& Lewicka, M. (2016). Nostalgia for communist times and autobiographical memory: Negative present or positive past? Political Psychology, 37, 677-693. https:// doi.org/10.1111/pops.12330.

Roediger, H. L., III, Mead, M. L., \& Bergman, E. T. (2001). Social contagion of memory. Psychonomic Bulletin \& Review, 8, 365-371. https://doi.org/10.3758/BF03196174.

Sahdra, B., \& Ross, M. (2007). Group identification and historical memory. Personality and Social Psychology Bulletin, 33, 384-395. https://doi.org/10.1177/ 0146167206296103.

Sani, F. (2010). Self continuity: Individual and collective perspectives. Psychology Press.

Sani, F., Bowe, M., \& Herrera, M. (2008). Perceived collective continuity and social wellbeing: Exploring the connections. European Journal of Social Psychology, 38, 365-374. https://doi.org/10.1002/ejsp.461.

Shaw, J. (2016). The memory illusion: Remembering, forgetting, and the science of false memory. Random House.

Smeekes, A. (2015). National nostalgia: A group-based emotion that benefits the in-group but hampers intergroup relations. International Journal of Intercultural Relations, 49, 54-67. https://doi.org/10.1002/ejsp.461.

Smeekes, A., Jetten, J., Verkuyten, M., Wohl, M. J. A., Jasinskaja-Lahti, I., Ariyanto, A., .. Butera, F. (2018). Regaining in-group continuity in times of anxiety about the group's future. Social Psychology, 49, 311-329. https://doi.org/10.1027/1864-9335/ a000350.

Smeekes, A., \& Verkuyten, M. (2013). Collective self-continuity, group identification and in group defense. Journal of Experimental Social Psychology, 49, 984-994. https://doi. org/10.1016/j.jesp.2013.06.004

Smeekes, A., Verkuyten, M., \& Martinovic, B. (2015). Longing for the country's good old days: National nostalgia, autochthony beliefs, and opposition to Muslim expressive rights. British Journal of Social Psychology, 54, 561-580. https://doi.org/10.1111/ bjso. 12097.

Statistics Poland (January 01, 2013). Przynależność narodowo-etniczna ludności - wyniki spisu ludności i mieszkań 2011. Materiały na konferencję prasową. [National and ethnic composition of Polish society - Results of the National Census 2011] Online: http:// stat.gov.pl/cps/rde/xbcr/gus/Przynale|-znosc narodowo-etniczna_w_2011_NSP.pdf.

Tajfel, H., \& Turner, J. C. (1986). An integrative theory of group conflict. In W. G. Austin, \& S. Worchel (Eds.). The social psychology of intergroup relations (pp. 7-24). Chicago, IL: Nelson-Hall.

Turner, R. N., Wildschut, T., \& Sedikides, C. (2018). Fighting ageism through nostalgia. European Journal of Social Psychology, 48, 196-208. https://doi.org/10.1002/ejsp. 2317.

Verkuyten, M. (2013). Justifying discrimination against Muslim immigrants: Out-group ideology and the five-step social identity model. British Journal of Social Psychology, 52(2), 345-360. https://doi.org/10.1111/j.2044-8309.2011.02081.x.

White, S. (2010). Soviet nostalgia and Russian politics. Journal of Eurasian Studies, 1, 1-9. https://doi.org/10.1016/j.euras.2009.11.003.

Wildschut, T., Bruder, M., Robertson, S., van Tilburg, W. A., \& Sedikides, C. (2014) Collective nostalgia: A group-level emotion that confers unique benefits on the group. Journal of Personality and Social Psychology, 107, 844-863. https://doi.org/10.1037/ a0037760.

Wilson, J. L. (2005). Nostalgia: Sanctuary of meaning. Lewisburg, PA, USA: Bucknell University Press.

Wohl, M. J. A., \& Branscombe, N. R. (2008). Remembering historical victimization: Collective guilt for current ingroup transgressions. Journal of Personality and Social Psychology, 94, 988-1006. https://doi.org/10.1037/0022-3514.94.6.988.

Wohl, M. J. A., Kim, H. S., Salmon, M., Santesso, D., Wildschut, T., \& Sedikides, C. (2018). Discontinuity-induced nostalgia improves the odds of a self-reported quit attempt among people living with addiction. Journal of Experimental Social Psychology, 75, 83-94. https://doi.org/10.1016/j.jesp.2017.11.011.

Wohl, M. J. A., Squires, E. C., \& Caouette, J. (2012). We were, we are, will we be? The social psychology of collective angst. Social Psychology and Personality Compass, 6, 379-391. https://doi.org/10.1111/j.1751-9004.2012.00437.x. 